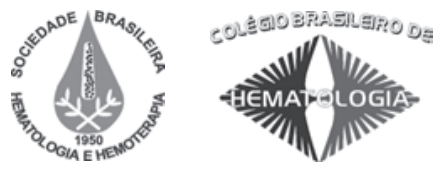

\title{
Discriminação alélica do fator V da coagulação por PCR em tempo real: diagnóstico simples e preciso
}

\author{
Allelic discrimination of coagulation factor $V$ by real time PCR: a simple and accurate \\ diagnosis
}

Aldemir B. Oliveira Filho ${ }^{1}$

Júlia F. Campos ${ }^{2}$

Magaly B. P. L. V. Lima

Farida C. B. C. Melo ${ }^{3}$

Washington B. Neves ${ }^{4}$

Raul A. M. Melo

José Alexandre R. Lemos
Dentre as doenças cardiovasculares, a trombose venosa (TV) destaca-se pela associação entre fatores de riscos adquiridos e fatores genéticos. A resistência hereditária à proteína $C$ ativada tem sido identificada como a principal causa dos casos de trombose venosa, sendo frequentemente associada à mutação fator $V$ Leiden (G1694A). Em indivíduos homozigotos, o risco de trombose venosa é 50 a 100 vezes maior que em pacientes homozigotos normais, enquanto em pacientes heterozigotos o risco é de 5 a 10 vezes. Baseado na necessidade de avaliação e acompanhamento de pacientes com casos de trombose venosa e prevenção de seus respectivos familiares, foi desenvolvido um método simples de discriminação alélica do fator $V$ da coagulação utilizando PCR em tempo real. Foram selecionados 67 pacientes com histórico de TV e 51 indivíduos sem histórico de TV. Primeiramente, a discriminação alélica do fator $V$ foi realizada através de PCR convencional seguida de digestão enzimática (Mnl). Posteriormente, o diagnóstico foi realizado por PCR em tempo real. Ambos os métodos foram baseados no polimorfismo G1691A, sendo no segundo utilizado fluoróforos VIC e FAM para marcar os nucleotídeos G e A, respectivamente. A técnica de PCR-RFLP foi utilizada para diagnosticar 95 indivíduos homozigotos normais, 21 heterozigotos e 2 homozigotos FVL. Utilizando PCR em tempo real foram obtidos os mesmos resultados. A máxima similaridade entre os resultados obtidos por PCR em tempo real e PCR-RFLP indicou precisão significativa do novo método de discriminação e visualização alélica do fator V. Rev. Bras. Hematol. Hemoter. 2009;31(1):25-28.

Palavras-chave: Trombose venosa; fator V Leiden; PCR em tempo real.

\section{Introdução}

Mundialmente, as doenças trombóticas constituem um problema de saúde de origem multifatorial e multigênica. As tromboses são caracterizadas pela formação aguda de trombos em veias e artérias. Dentre as doenças cardiovasculares, a trombose venosa (TV) destaca-se pela asso- ciação entre fatores de riscos adquiridos, como imobilização prolongada, cirurgias, fraturas, gestação, etc, e fatores genéticos, mutações nos genes da proteína C, proteína S e antitrombina III. ${ }^{1,2,3}$

A resistência hereditária à proteína $\mathrm{C}$ ativada (RPCA) tem sido identificada como a principal causa da maioria dos casos de trombose venosa, 95\% dos casos de RPCA estão

\footnotetext{
${ }^{1}$ Biomédico.

${ }^{2}$ Bióloga, Fundação Hemope.

${ }^{3}$ Farmacêutica-Bioquímica, Fundação Hemope.

${ }^{4}$ Químico, Fundação Hemope.

${ }^{5}$ Professor Adjunto da Faculdade de Ciências Médicas da Universidade de Pernambuco.

${ }^{6}$ Professor Adjunto do Instituto de Ciências Biológicas da Universidade Federal do Pará e Pesquisador convidado da Fundação Hemopa.

Correspondência: José Alexandre R. Lemos

Laboratório de Biologia Celular e Molecular, Fundação Centro de Hematologia e Hemoterapia do Pará, Hemopa.

Travessa Padre Eutíquio, 2109 - Batista Campos

66033-000 - Belém-PA - Brasil

Email: alexandre.lemos@me.com
} 
associados à mutação pontual G1691A no exon 10 do gene do fator $\mathrm{V}$ da coagulação, 0 fator V Leiden (FVL). ${ }^{4,5}$ Esse polimorfismo não-sinonímico causa a perda da clivagem do fator $\mathrm{V}$, gerando um quadro de hipercoagulopatia e, consequentemente, aumentando o risco de trombose venosa. ${ }^{3,6}$ Em indivíduos homozigotos FVL, o risco de trombose venosa é cinquenta a cem vezes maior que em pacientes homozigotos normais, enquanto em pacientes heterozigotos o risco é de cinco a dez vezes. ${ }^{6}$ As maiores incidências de FVL são detectadas em países europeus. ${ }^{7}$ No Brasil, diversas pesquisas indicaram que a frequência do FVL poderia variar de 1,6\% a 2,6\%. ${ }^{8,9,10}$ Entretanto, tal incidência torna-se maior na população do estado de Pernambuco (13,3\%), sendo evidenciada a potencialização do risco de TV através da associação FVL e genótipo sanguíneo não-O..$^{11,12}$

Baseado na necessidade de avaliação e acompanhamento de pacientes com casos de trombose venosa e prevenção de seus respectivos familiares, este trabalho demonstrou um modelo simples e preciso de discriminação alélica do fator $\mathrm{V}$ da coagulação (G1691A) utilizando PCR em tempo real.

Este estudo foi constituído por 67 pacientes com histórico de TV e 51 indivíduos sem histórico de tal evento, ambos os grupos atendidos pelo Ambulatório de Doenças Trombóticas do Hospital da Fundação Centro de Hematologia e Hemoterapia de Pernambuco (Hemope). Foram coletados de cada participante 3-5 $\mathrm{mL}$ de sangue em tubo estéril (Vacutainer) contendo ácido etilenodiamino tetracético (EDTA), sendo posteriormente extraído o DNA utilizando-se o kit comercial DNA GFX Genomic Blood DNA Purification Kit (Amersham Biosciences) seguindo as recomendações do fabricante. Como experimento controle para discriminação alélica do fator $V$ foi utilizado PCR-RFLP seguindo o protocolo de Ramos. ${ }^{10} \mathrm{~A}$ digestão originou fragmentos de 120 e $42 \mathrm{pb}$ quando $\mathrm{G}$ estava presente na posição 1691 (alelo normal), enquanto a substituição G A (alelo mutado, FVL) resultou em fragmentos de 162 pb para os portadores homozigotos e fragmentos de 162, 120 e $42 \mathrm{pb}$ para os portadores heterozigotos para a mutação, resultado da perda do sítio de clivagem pela enzima MnlI.

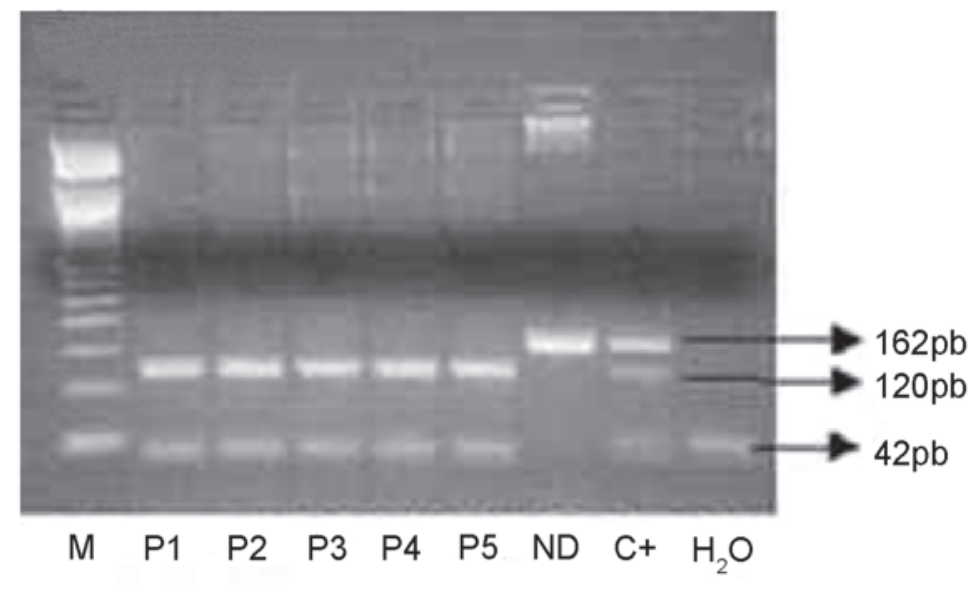

Figura 1

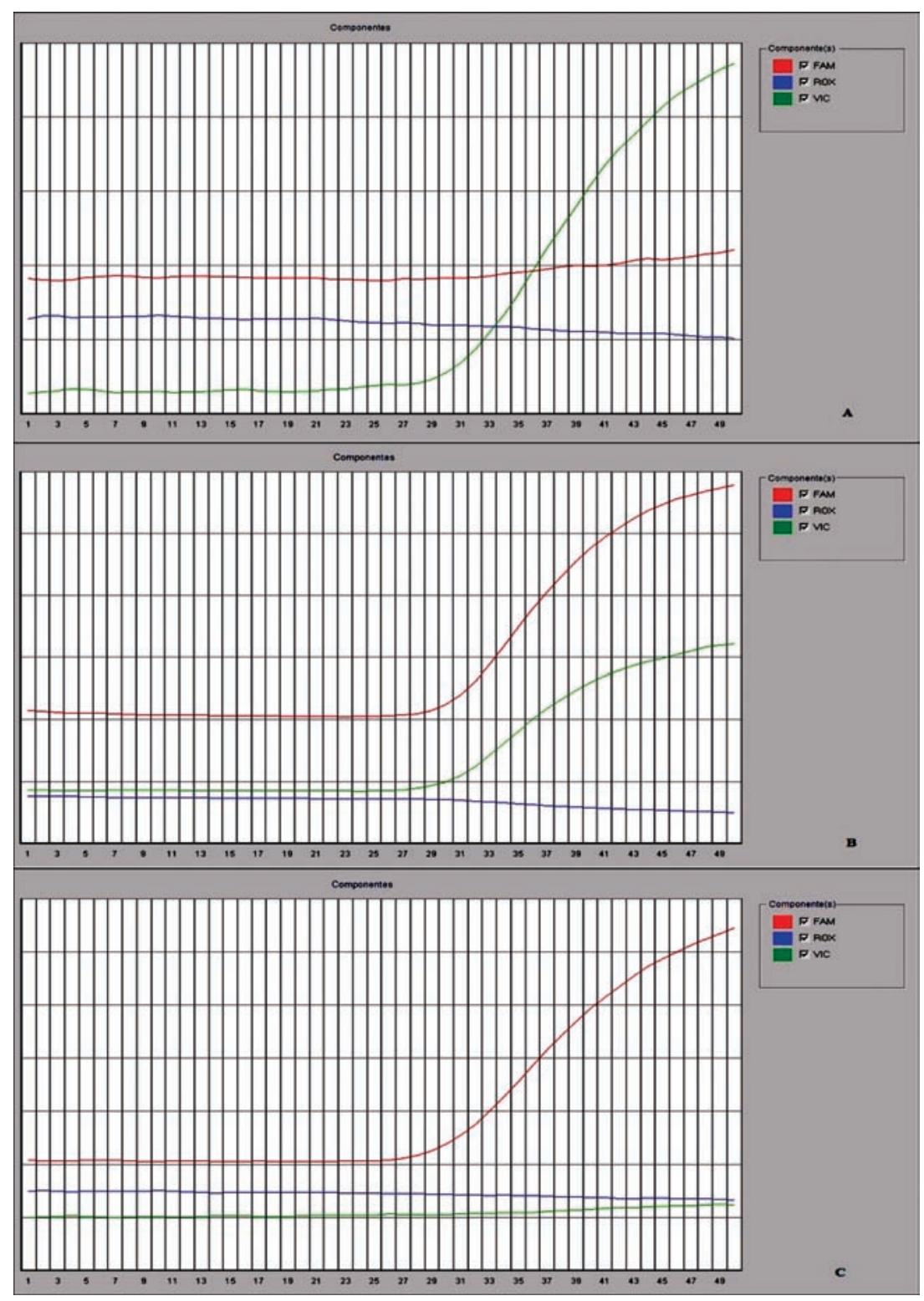

Figura 2 
Por outro lado, a discriminação alélica do fator $\mathrm{V}$ por PCR em tempo real foi realizada utilizando aparelho ABI Prism 7000 e kit comercial TaqMan Universal PCR Master Mix, ambos da Applied Biosystems. Cada reação foi constituída de 12,5 $\mu \mathrm{L}$ de tampão universal PCR master mix 2x, $0,5 \mu \mathrm{L}(10 \mathrm{mM})$ da solução contendo iniciadores (5'CTGGGCTAATAGGACTACTT CTAATCTGT-3' e 5'CATGTTCTAGCCAGAAGAAATT CT CAGA-3') e sondas alelo-específico (VIC-AGGCGAGGA ATAC-MGB e FAMCAGGCAAGGAATAC-MGB), 9,0 $\mu \mathrm{L}$ de água deionizada e $3 \mu \mathrm{L}$ de amostra de DNA. A amplificação foi feita utilizando a seguinte ciclagem: $50^{\circ} \mathrm{C} / 2 \mathrm{~min}, 95^{\circ} \mathrm{C} / 10 \mathrm{~min}$ e 50 ciclos de $95^{\circ} \mathrm{C} / 15 \mathrm{~s}$ e $60^{\circ} \mathrm{C} / 1 \mathrm{~min}$. A mistura contendo iniciadores e sondas foi sintetizada por encomenda à empresa Applied Biosystems. A discriminação alélica do fator V por PCR em tempo real foi baseada no polimorfismo nucleotídico único G1691A, sendo utilizado fluoróforos VIC e FAM para marcar os nucleotídeos G (alelo normal) e A (alelo mutado, FVL), respectivamente.

Por PCR-RFLP foram diagnosticados 95 indivíduos homozigotos normais, 21 heterozigotos e 2 homozigotos FVL (Figura 1). Utilizando-se PCR em tempo real foram obtidos resultados idênticos (Figura 2). A máxima similaridade entre os diagnósticos obtidos pelos dois métodos (PCR em tempo real e PCR-RFLP) indicaram precisão significativa do novo experimento de discriminação alélica do fator V da coagulação.

A detecção do fator V Leiden por PCR em tempo real utilizando o sistema TaqMan foi baseada na hibridização de oligonucleotídeo alelo-específico com diferenciação de uma única base $(\mathrm{G} \rightarrow \mathrm{A})$, sendo a identificação alélica realizada a partir de curva de utilização dos respectivos oligos durante a reação em cadeia da polimerase (Figura 2). Happich ${ }^{13} \mathrm{e}$ Barrach $^{14}$ também desenvolveram metodologias para discriminação alélica do fator $\mathrm{V}$ da coagulação baseadas na mutação G1691A utilizando PCR em tempo real e PCR-RFLP, respectivamente. Entretanto, a performance da nossa metodologia reduziu o tempo de análise, eliminou etapas laboriosas de pós-PCR e facilitou demasiadamente a visualização do resultado sem alterar a precisão do diagnóstico. Sendo que, para estabelecer as condições de detecção do experimento foi necessário somente ajustar as concentrações dos iniciadores e dos oligonucleotídeos alelo-específicos compatíveis com a amplificação do fragmento alvo. Não houve a necessidade de alterar qualquer outro parâmetro da reação. Além disso, contrastando com a PCR-RFLP, ${ }^{14}$ a detecção de ambos os alelos foi realizada numa única etapa e num único tubo, fato que reduziu potencialmente o risco de contaminação por produto de PCR, haja vista que o diagnóstico é realizado numa única etapa sem a necessidade de abertura de tubos para análise de produto de PCR.

Nossa metodologia ainda apresenta a vantagem de discriminar alelos sem necessitar de formação dos agrupamentos homozigoto normal, heterozigoto e homozigoto FVL utilizada por Happich, ${ }^{13}$ o diagnóstico é individualizado e visualizado através das curvas de utilização dos oligonucleotídeos marcados com fluorescência. Em suma, este trabalho mostrou que a discriminação e a visualização alélica do fator V por PCR em tempo real pode ser realizada por um método simples, preciso e seguro contra possível contaminação.

\begin{abstract}
Among cardiovascular diseases, venous thrombosis is important due to the association between acquired and genetic risks factors. Hereditary resistance to activated protein $C$ has been identified as the main cause of venous thrombosis, and is frequently associated to the factor $V$ Leiden mutation (G1694A). In homozygotic individuals, the risk of venous thrombosis is 50 to 100 times higher that in normal patients, while in heterozygotic patients the risk is 5 to 10 times higher. Based on the need of evaluation and follow up of patients with venous thrombosis and prevention in their respective families, a simple method of allelic discrimination of coagulation $V$ factor was developed using real time PCR. Sixtyseven patients with a history of venous thrombosis and 51 individuals without venous thrombosis were selected for this study. First, identification of the factor $V$ allele was achieved through conventional PCR followed by enzymatic digestion ( $\mathrm{Mnl}$ ). Subsequently, diagnosis was attained by real time PCR. Both the methods investigated the G1691A polymorphism using VIC and FAM fluorophores to mark nucleotides $G$ and A, respectively. By PCR-RFLP, 95 individuals were diagnosed as normal homozygotes, 21 as heterozygotes and 2 as homozygotic factor $V$ Leiden individuals. The same results were obtained using real time PCR. Maximum similarity between the results of real time PCR and PCR-RFLP indicates high precision of the new method for allelic identification and visualization of factor $V$ Leiden. Rev. Bras. Hematol. Hemoter. 2009;31(1):25-28.
\end{abstract}

Key words: Venous thrombosis; factor V Leiden; real time PCR.

\section{Referências Bibliográficas}

1. Bertina RM. Molecular risk factors for thrombosis. Thromb Haemost. 1999;82(2):601-9.

2. Kalafatis M, Mann KG. Factor VLeiden and thrombophilia. Arterioscler Thromb Vasc Biol. 1997;17(4):620-7.

3. Lane DA, Grant PJ. Role of hemostatic gene polymorphisms in venous and arterial thrombotic disease. Blood. 2000;95(5): 1517-32.

4. Bertina RM, Koeleman BP, Koster T, Rosendaal FR, Dirven RJ, de Ronde $\mathrm{H}$, et al. Mutation in blood coagulation factor $\mathrm{V}$ associated with resistance to activated protein C. Nature. 1994; 369 (6475): 64-7.

5. de Visser MC, Rosendaal FR, Bertina RM. A reduced sensitivity for activated protein $\mathrm{C}$ in the absence of factor $\mathrm{V}$ Leiden increases the risk of venous thrombosis. Blood. 1999;93(4):1271-6.

6. Dahlbäck B. New molecular insights into the genetics of thrombophilia. Resistance to activated protein C caused by Arg506 to Gln mutation in factor $\mathrm{V}$ as a pathogenic risk factor for venous thrombosis. Thromb Haemost. 1995; 74(1): 139-48. 
7. Lucotte G, Mercier G. Population genetics of factor V Leiden in Europe. Blood Cells Mol Dis. 2001;27(2):362-7.

8. Arruda VR, Annichino-Bizzacchi JM, Costa FF, Reitsma PH. Factor V Leiden (FVQ 506) is common in a Brazilian population. Am J Hematol. 1995;49(3):242-3.

9. Franco RF, Elion J, Santos SEB, Araújo AG, Tavella MH, Zago MA. Heterogeneous ethnic distribution of the factor V Leiden mutation. Genet Mol Biol. 1999;22(2):143-5.

10. Yoshioka FKN, Araújo AG, Tavella MH, Hamoy IG, Guerreiro JF. Prevalence of hereditary risk factors for thrombophilia in Belém, Brazilian Amazon. Genet Mol Biol. 2006;29(1):38-40.

11. Ramos CPS, Campos JF, Melo FCBC, Neves WB, Santos ME, Araújo FA, et al. Freqüência do fator V Leiden em indivíduos sob investigação de trombofilia, Recife, Pernambuco, Brasil. Rev Bras Hematol Hemoter. 2006;28(2):131-4.

12. Lima MPBLV, Oliveira Filho AB, Campos JF, Melo FCBC, Neves WB, Magalhães MG, et al. Risco significativo de trombose venosa em portadores dos genótipos fator $\mathrm{V}$ Leiden e grupo sanguíneo não-O em Pernambuco, Nordeste do Brasil. Rev Bras Hematol Hemoter 2007;29(Suppl.3):99.

13. Happich D, Schwaab R, Hanfland P, Hoernschemeyer D. Allelic discrimination of factor V Leiden using a 5' nuclease assay. Thromb Haemost. 1999 Oct;82(4):1294-6.

14. Barrach FH, Pardini MIMC, Sales MM, Maffei FHA, Machado PEA. Detecção de mutação no gene do fator V (fator V Leiden) em pacientes com trombose venosa. J Bras Patol Med Lab. 2001; 37(2):88-92.

Suporte Financeiro: Fundação Centro de Hematologia e Hemoterapia do Pará, Hemopa.

Avaliação: Editor e dois revisores externos

Conflito de interesse: não declarado

Recebido: 17/06/2008

Aceito: 16/09/2008 